\title{
How latent patterns of interprofessional working may lead to delays in discharge from hospital of older people living with frailty - 'Patient more confused than usual?'
}

\author{
Sabi Redwood ${ }^{1 \star}$ (D), Heather Brant ${ }^{1}$, Adriano Maluf ${ }^{2}$, Gill Combes ${ }^{2}$, Kyra Neubauer ${ }^{1}$, \\ Clare Thomas ${ }^{1}$, Sarah Damery ${ }^{2}$, Nadine Murigu${ }^{1}$, Elizabeth Hill ${ }^{1}$, Sheila Greenfield ${ }^{2}$ and \\ Jenny L. Donovan ${ }^{1}$ \\ ${ }^{1}$ Bristol Medical School, Population Health Sciences, University of Bristol, Bristol, UK and National \\ Institute for Health Research Applied Research Collaboration West (ARC West) and ${ }^{2}$ Institute of Applied \\ Health Research, University of Birmingham, Birmingham, UK and National Institute for Health Research \\ Applied Research Collaboration West Midlands (ARC West Midlands) \\ ${ }^{*}$ Corresponding author. Email: sabi.redwood@bristol.ac.uk
}

(Accepted 28 April 2021; first published online 8 June 2021)

\begin{abstract}
Unnecessarily delayed discharges from hospital of older people living with frailty can have negative consequences for their health and add significant costs to health services. We report on an ethnographic study at two English hospitals and their respective health and social care systems where we followed 37 patient journeys. The study aim was to understand why delays occur. Our findings indicate that working practices in the study hospitals may have inadvertently contributed to delays. While many pieces of patients' clinical and social information were collected, recorded and accessed in different ways by different professionals, to facilitate a discharge, these pieces needed to be re-found, integrated and re-constructed. A key component of this process was information related to patients' social, family and functional background. This was often missing, not accessed or perceived to be of low value compared to other more readily available clinical information. Patients' re-construction was thus often incomplete, or insufficient to reduce the clinical and prognostic uncertainty associated with frailty and to manage risks inherent in older people's discharge. Where this key component was present and integrated into decision-making in multi-disciplinary team working, uncertainty and risk were managed more constructively and sometimes avoided an escalation of care needs.
\end{abstract}

Keywords: hospital discharge/delayed transfer of care; frailty; multi-disciplinary teams; ethnography

\section{Background}

The discharge of older people living with frailty $\left(O P L W F^{1}\right)$ is often delayed when they no longer need hospital care (National Audit Office, 2016). This has

\footnotetext{
(C) The Author(s), 2021. Published by Cambridge University Press. This is an Open Access article, distributed under the terms of the Creative Commons Attribution licence (http://creativecommons.org/licenses/by/4.0/), which permits unrestricted re-use, distribution, and reproduction in any medium, provided the original work is properly cited.
} 
potentially negative consequences for their health and independence, and adds significant costs to health services (Bate, 2017). Despite initiatives to reduce unnecessarily delayed transfers of care from hospitals, they remain problematic. In England, reasons for delays are attributed to either the National Health Service (NHS) or Local Authority social care (NHS England, 2017b). In reality, delayed discharges are often the result of complex processes across both sectors, including assessments for additional support and care, the sourcing of equipment and home care packages, and access to non-hospital care. Disagreements among family members and between patients/families and providers about onward care also contribute to delays (King's Fund, 2018).

The risk of having a delayed discharge increases when a patient is admitted as an emergency (Jasinarachchi et al., 2009). While many people live into a healthy old age, others require acute care, especially when over the age of 85 , and presenting with multi-morbidities, polypharmacy, cognitive impairment and disability (Wilson et al., 2015). Clinical decision-making is often challenging when assessing and managing acutely ill older people in the Emergency Department due to the complexity of their physical conditions and social circumstances, so that many are admitted to a hospital bed (NHS England, 2017a). Once in hospital, older people are vulnerable to hospital-acquired infections, falls, confusion, pressure sores, malnutrition, the withdrawal of support systems at home, and loss of strength and confidence to manage independently (Oliver et al., 2014). Yet while a lengthy hospital stay poses the greatest health risks for older people, they are the group most likely to be delayed in hospital when they no longer require acute care.

This delay can have distressing consequences for OPLWF, affecting their longterm health and independence (Kortebein, 2009; Corrigan et al., 2016). Furthermore, there is evidence to suggest that longer hospital stays for OPLWF can lead to worse health outcomes and an increase in their care needs on discharge. For example, physical deconditioning and functional decline, and 'iatrogenic disability', defined as avoidable dependence, occurs in 30-60 per cent of patients because of hospitalisation which is exacerbated by longer stays in hospital (Lafont et al., 2011). For OPLWF, the longer the delay, the greater the chance of dependency and institutionalisation (Bauer et al., 2009).

The need to improve the movement of patients through the health and social care systems with a focus on reducing bottlenecks, waste, delays and duplication to improve the quality of patients' and service users' experiences has been recognised (The Health Foundation, 2013; Fillingham et al., 2016; Crisp et al., 2020). Yet while there are guidelines and best practice principles indicating how discharges for OPLWF should be organised and co-ordinated (National Audit Office, 2016; Royal College of General Practitioners and British Geriatric Society, 2016), there are few studies addressing how these may be put into practice systematically across hospital services and little is known about the barriers to joint working for staff in different organisational settings. Hospital discharge requires complex patterns of care organisation by different professionals and organisations which often lead to delay, especially for older people whose needs are frequently multifaceted. System and policy structures such as financial incentives and legislative levers to drive integration are clearly important to creating environments conducive to reducing complexity and enabling multi-disciplinary working and care co-ordination. However, 
interactions between professionals are non-linear, dynamic and recursive, and cultural differences between health and social care agencies persist (Waring et al., 2015). This complexity in practice needs to be negotiated in ways that go beyond agreed policies and guidelines. What is required in order to develop solutions or interventions is a nuanced understanding of how this complexity is experienced, negotiated and managed by staff involved in co-ordinating hospital discharges for OPLWF, and patients and family members. The study aim was to understand why delays occur and identify obstacles that may be amenable to local solutions that could also have wider application across other health and care systems. Such insights will improve the quality of life of OPLWF by ensuring that they receive timely compassionate support and care in the most appropriate setting for their needs, and also increase efficiency by reducing numbers of hospital days 'lost' to unnecessarily delayed discharges.

\section{Methods}

\section{Design and setting}

This ethnographic study was conducted at two large NHS hospitals in two English cities and their respective systems of health and care delivery, including community and social care services. All members of the research team had experience of conducting focused ethnography in a health-care setting and held a doctoral-level qualification. At the centre of the study were patient pathways - the individual patient journeys from an unplanned hospital admission to post-hospital care, and their flow through the hospital system. Drawing on the insights by Waring et al. (2014) that hospital discharge is predicated on complex situations of knowledge-sharing across the entire care journey, the study focused on understanding interactions where professionals came together to make specific decisions and address tasks related to discharge (Waring et al., 2014). The study was planned and designed with a range of public contributors who are members of the National Institute for Health Research Applied Research Collaboration (NIHR ARC) West Patient and Public Involvement team; two public contributors with lived experience of delayed hospital discharge were part of the research team and contributed to research team meetings.

\section{Participant recruitment}

The risk of delayed discharge increases for patients being admitted as emergencies. Therefore, study participants were identified by clinical teams in both hospitals as close to their unplanned or emergency admission as possible. Patients over the age of 80 years with frailty at moderate-severe level (based on the three-point FRAILsafe scale ${ }^{2}$; Papoutsi et al., 2018) were eligible. We sampled purposively to achieve a variation sample in terms of gender, ethnicity and social connectedness, with half of the patients coming from geriatric care and half from other nongeriatric care. We also purposively sampled key individuals involved in discharge decisions including: medical consultants, clinical staff, nursing staff, therapy staff, social workers, discharge co-ordinators and community service leads.

Following an initial approach by clinical staff, the researcher provided written and verbal information and sought formal consent from the patient and/or family 
and carers to participate by being observed and an interview. It was not always possible to seek full and informed consent prior to data collection as the patient was recruited following an emergency admission. Therefore verbal consent was sought from the patient where possible to observe the meeting. Retrospective written consent was sought later either from the patient or a personal or a nominated consultee, a term used to indicate a person who will make a decision for or on behalf of a person who lacks mental capacity in accordance with the Department of Health's guidance on nominating a consultee for research involving adults who lack capacity to consent (Department of Health, 2007). If the participant or their consultee declined participation, all data collected related to the encounter were deleted. Out of the total of 37 patients, 11 were male and 26 female; only two were not White British. Thirteen patients lived in residential care or assisted living, eight had care packages in situ before admission, six patients lived alone with little support, and 14 lived alone with spouse and family support, or lived with spouse or family. Of the latter group, some were cared for by their spouses, others were carers for their spouse. Length of stay ranged from two to 104 days. The mean length of stay in site A was 16 days with a median of 14 days; the mean length of stay at site B was 28.4 days with a median of 26 days. Ten patients had a family or nominated consultee supporting consent to participate in the study. A summary of patient participants' characteristics is provided in Table 1.

\section{Data collection}

Following consent procedures, researchers followed patients to the wards, observed meetings, and accessed patients' records to assist in the compilation of timelines and to gather information about clinical decision-making.

Data collected for each patient included the following. (a) Information about the ordering of diagnostic tests and assessments, and their completion; clinical incidents relating to falls or sudden deterioration, new diagnoses, documented meetings with patients and/or families/carers, clinical decisions, information conveyed to patients and/or families/carers. (b) Non-participant observational data which was guided by an observation guide (see the online supplementary material) to understand the articulation work of integrating and meshing different tasks and types of professional and organisational processes required to achieve co-ordinated patient discharges. This included observational data during key interactions such as multi-disciplinary team (MDT) meetings, ward rounds, team discussions and other meetings; and during times of 'shadowing' individuals in key roles contributing to the planning and co-ordination of hospital discharges. Observations were supplemented by informal conversations with clinical and ward-level staff to clarify observed activity or discuss a procedure and elicit their perspectives and interpretations. (c) Formal semi-structured interviews with health and social care professionals and local system leads involved in discharge processes, and also with patients and families after discharge to elicit their experiences and understanding of their hospital stay.

A flexible topic guide was used to shape the formal semi-structured interviews. The interviews with patients were conducted in their own home. Those with family members and carers were conducted either in the hospital, in their own home or by 


\begin{tabular}{|c|c|c|c|c|c|c|c|c|}
\hline Site & ID & $\begin{array}{l}\text { Personal or } \\
\text { nominated } \\
\text { consultee }\end{array}$ & Gender & Age & Supporting network & $\begin{array}{l}\text { Living } \\
\text { arrangements }\end{array}$ & Ethnicity & $\begin{array}{l}\text { Length of } \\
\text { stay (days) }\end{array}$ \\
\hline$A$ & P01 & & Male & 84 & Wife is main carer & Lived with wife & White British & 12 \\
\hline A & P02 & & Female & 86 & $\begin{array}{l}\text { Supported by } \\
\text { daughter-in-law }\end{array}$ & Lived alone & White British & 15 \\
\hline A & P03 & Yes, consultant & Female & 95 & & Care home & White British & 2 \\
\hline A & P04 & & Female & 88 & $\begin{array}{l}\text { Supported by live-in-carer; no } \\
\text { family lived locally }\end{array}$ & Lived alone & White British & 15 \\
\hline A & P05 & & Female & 84 & $\begin{array}{l}\text { Supported by an extensive } \\
\text { family }\end{array}$ & $\begin{array}{l}\text { Lived alone, } \\
\text { husband had just } \\
\text { died }\end{array}$ & White British & 11 \\
\hline A & P06 & & Male & 82 & Son is main carer & Assisted living & White British & 37 \\
\hline A & P07 & Yes, consultant & Female & 85 & Daughter is main carer & Assisted living & White British & 20 \\
\hline A & P08 & & Male & 83 & & Lived with wife & White British & 2 \\
\hline A & P09 & Yes, consultant & Male & 88 & Daughter is main carer & Assisted living & White British & 31 \\
\hline A & P10 & & Male & 80 & & Lived with wife & White British & 5 \\
\hline A & P11 & & Female & 94 & No next of kin or support & Lived alone & White British & 19 \\
\hline A & P12 & & Female & 91 & & Nursing home & White British & 4 \\
\hline A & $\mathrm{P} 13$ & & Male & 96 & Daughter is main carer & Lived with wife & White British & 14 \\
\hline A & P14 & Yes, consultant & Female & 87 & & Nursing home & White British & 4 \\
\hline A & P15 & & Female & 87 & & Lived alone & White British & 14 \\
\hline A & P16 & & Female & 80 & Supported by two daughters & Lived with husband & White British & 56 \\
\hline$A$ & $\mathrm{P} 17$ & & Female & 80 & & Lived with husband & White British & 10 \\
\hline
\end{tabular}




\begin{tabular}{|c|c|c|c|c|c|c|c|c|}
\hline$A$ & $\mathrm{P} 18$ & & Female & 85 & Daughter is main carer & Lived alone & White British & 17 \\
\hline B & $\mathrm{P} 2$ & $\begin{array}{l}\text { Yes, daughter } \\
\text { and doctor }\end{array}$ & Male & 91 & $\begin{array}{l}\text { Divorced; supported by one } \\
\text { daughter }\end{array}$ & Care home & White British & 33 \\
\hline B & P3 & & Female & 83 & Supported by daughter & Assisted living & White British & 10 \\
\hline B & P4 & $\begin{array}{l}\text { Yes, next of kin } \\
\text { (friend) }\end{array}$ & Female & 91 & $\begin{array}{l}\text { Supported by former } \\
\text { neighbour; no family }\end{array}$ & Assisted living & White British & 49 \\
\hline B & P5 & Yes, son & Female & 91 & Supported by family & Care home & $\begin{array}{l}\text { Syrian - does not } \\
\text { speak English }\end{array}$ & 17 \\
\hline B & P6 & & Female & 95 & $\begin{array}{l}\text { Sister lived in the same } \\
\text { complex; son lives half of year } \\
\text { abroad }\end{array}$ & Assisted living & White British & 27 \\
\hline B & P8 & & Male & 89 & $\begin{array}{l}\text { Sister lived in the same } \\
\text { complex; sons live abroad }\end{array}$ & Assisted living & White British & 42 \\
\hline B & P9 & & Female & 95 & $\begin{array}{l}\text { Supported by daughter and } \\
\text { family }\end{array}$ & $\begin{array}{l}\text { Lived with } \\
\text { daughter }\end{array}$ & White (Irish) & 8 \\
\hline B & $\mathrm{P} 10$ & & Male & 86 & Supported by nephew & Lived alone & White British & 10 \\
\hline B & P11 & & Male & 86 & No next of kin or support & Assisted living & White British & 13 \\
\hline B & P12 & & Female & 93 & No next of kin or support & & White British & 30 \\
\hline B & $\mathrm{P} 15$ & & Female & 82 & $\begin{array}{l}\text { Supported by daughter who } \\
\text { lives away }\end{array}$ & & White British & 26 \\
\hline B & $\mathrm{P} 17$ & Yes, daughter & Female & 99 & Supported by wider family & $\begin{array}{l}\text { Lived with } \\
\text { daughter }\end{array}$ & White British & 19 \\
\hline B & P18 & & Female & 86 & $\begin{array}{l}\text { Supported by son and two } \\
\text { daughters, who all live away }\end{array}$ & & White British & 12 \\
\hline B & $\mathrm{P} 20$ & & Male & 81 & & $\begin{array}{l}\text { Lived with } \\
\text { daughter }\end{array}$ & $\begin{array}{l}\text { Pakistani - does } \\
\text { not speak } \\
\text { English }\end{array}$ & 30 \\
\hline
\end{tabular}


Table 1. (Continued.)

\begin{tabular}{|c|c|c|c|c|c|c|c|c|}
\hline Site & ID & $\begin{array}{l}\text { Personal or } \\
\text { nominated } \\
\text { consultee }\end{array}$ & Gender & Age & Supporting network & $\begin{array}{l}\text { Living } \\
\text { arrangements }\end{array}$ & Ethnicity & $\begin{array}{l}\text { Length of } \\
\text { stay (days) }\end{array}$ \\
\hline B & $\mathrm{P} 21$ & & Female & 80 & $\begin{array}{l}\text { Patient supported by friends } \\
\text { who live in the same complex } \\
\text { of flats }\end{array}$ & Assisted living & White British & 26 \\
\hline B & $\mathrm{P} 22$ & Yes, doctor & Female & 82 & $\begin{array}{l}\text { Son lives distant to the } \\
\text { patient; no other support }\end{array}$ & & White British & 104 \\
\hline B & P23 & & Female & 87 & Supported by two daughters & & White British & 37 \\
\hline B & P24 & & Female & 84 & $\begin{array}{l}\text { Supported by son and } \\
\text { daughter who live in the } \\
\text { same area }\end{array}$ & Lived with husband & White British & 16 \\
\hline B & P25 & Yes, nephew & Female & 86 & Nephew is the main carer & Lived with nephew & White British & 31 \\
\hline
\end{tabular}


telephone. Interviews with staff were held either in their workplace or by telephone. The interviews were between 18 and 47 minutes in length with an average of 35 minutes. They were recorded using a digital voice recorder, transcribed and anonymised to protect confidentiality.

Researchers were regularly debriefed by team members following observations and interviews to discuss initial impressions and help make sense of the data they collected. This ensured that data collection remained focused on the research questions, and helped to identify gaps and inform subsequent data collection (Schoepfle and Werner, 1999). The debriefings focused on problem solving around access to participants or data, ethical and practical challenges, early analytic ideas, reflexivity (Alvesson and Sköldberg, 2018) and the wellbeing of the researcher.

In total, we followed 37 patients over 390 hours of direct observations over a period of 18-22 weeks between October 2018 and March 2019. We conducted 66 semi-structured interviews with patients, family members, and hospital-based and community professionals and managers. A breakdown of data collected at each site is provided in Table 2.

\section{Research ethics}

We designed recruitment to the study inclusively so that people with dementia and other cognitive limitations could take part if they wished (through the use of a personal or a nominated consultee as described above) and provided translation services for those for whom English was not their first language, utilising the existing translation services within the hospital trusts. The study was approved by the West Midlands - Coventry \& Warwickshire Research Ethics Committee.

\section{Data analysis}

Data collection and analysis were carried out concurrently and iteratively using the constant comparative method (Charmaz, 2006). Fieldnote and interview data were transcribed and imported into QSR NVivo qualitative data analysis software to support coding and data management.

Individual patient cases were compiled to understand the journey from admission to post-hospital care from the patients' and families'/carers' perspective. Data from each patient case, including timeline data from the patient records, field notes from observations of meetings and interactions with staff were analysed to map the timings of their pathway through the system, and their views, emotional responses and interpretation of these events and activities. Descriptive accounts of the patient pathway through the system and of patient and family perceptions and experiences were produced. Data from interviews with health and social care professionals, local system leads, and patients and family members, and field notes from meeting observations were analysed by the local site researchers using thematic analysis (Braun and Clarke, 2006, 2019) to develop an iteratively and inductively derived coding frame. The codes were further refined through weekly study team meetings at each site. Data analysis was initially carried out separately at each site to enable specific feedback to local stakeholders.

The combined datasets were synthesised at two-monthly meetings with the wider study team across both sites during the data analysis phase. During these 
Table 2. Data collection

\begin{tabular}{|c|c|c|c|}
\hline & Site A & Site B & Total \\
\hline $\begin{array}{l}\text { Number of hours of observation in } \\
\text { hospital (approximately) }\end{array}$ & 190 & 200 & 390 \\
\hline $\begin{array}{l}\text { Length of time of observation in } \\
\text { hospital }\end{array}$ & 18 weeks (October to January) & 22 weeks (November to March) & Period covered: October 2018 to March 2019 \\
\hline \multicolumn{4}{|l|}{$\begin{array}{l}\text { Formal interviews (not part of } \\
\text { observations): }\end{array}$} \\
\hline Patients & 5 & 3 & 8 \\
\hline Family members & 4 & 9 & 13 \\
\hline General practitioners & 8 & 3 & 11 \\
\hline Social workers & 1 & 5 & 6 \\
\hline Occupational therapists ${ }^{1}$ & 0 & 1 & 1 \\
\hline Pharmacists & 0 & 2 & 2 \\
\hline Operational managers & 1 & 0 & 1 \\
\hline Informants $^{2}$ & 5 & 3 & 8 \\
\hline
\end{tabular}

Notes: 1 . While formal interviews with therapy staff were difficult to organise due to pressures on their time, researchers were able to speak to and shadow these staff as part of the observational work recorded in fieldnotes. 2. From Local Authorities or Clinical Commissioning Groups. 
collaborative discussions, themes were proposed, tested through constant comparison, and generated for descriptive and explanatory understandings of discharge planning and organisation which were iteratively developed and refined. These were verified at steering group meetings.

\section{Results}

The patient journeys revealed a range of sources of delays as patients had to wait for things to happen or to become available. For example, investigations and specialist team reviews took time; there were delays in the provision of appropriate equipment and home oxygen; difficulties in finding care packages to meet patients' needs and limited availability of 'step down' beds for patients who were medically stable and suitable for discharge inevitably led to delays; and assessments by care providers such as nursing homes were often not carried out as quickly as desired by hospital staff. However, the data also pointed to taken-for-granted working practices and communication methods between different professionals and across organisational boundaries that also inadvertently generated delays in patients being discharged. In the following section, we describe what happened to patients during their admission to hospital as 'de-construction', a process by which clinical and non-clinical pieces of information about a patient were gathered by a range of health-care professionals and staff at different times and in different ways. When discharge planning began, there were attempts at the patient's 're-construction', the re-integration of the pieces of information previously collected, to enable discharge planning. These processes reflected routine patterns of working which shaped the ways in which health and social care professionals dealt with uncertainty and risk inherent in caring for OPLWF (Hoogendijk et al., 2019) and had clear effects on patients' discharges. We support the de-construction/re-construction processes with data excerpts from interviews and fieldnotes. The findings reported were seen across both sites and are illustrated by the most fitting quote(s). We use fewer fieldnote excerpts because these were highly detailed and were used predominantly for collating the patient pathways which are not reported here.

\section{De-construction}

Patients participating in this study were taken to hospital following typical crises experienced by OPLWF - falls, infections, and 'funny turns' such as changes in alertness, for example. As with all unplanned hospital admissions, a process of information gathering, history taking, clinical assessments, investigations and laboratory tests started in the Emergency Department to enable diagnosis and treatment. Apart from clinical information, narrative accounts relating to the events leading up to the crisis and attendance at the Emergency Department, patients' wishes, their usual functional capabilities, their level of awareness and understanding, social and family circumstances, networks of friends and family, and the availability of support were collected from patients themselves, or more often as a 'collateral history' from relatives or carers, particularly for those unable to provide accurate information themselves. We found that similar types of information were collected, often repeatedly, by different professionals, stored and retrieved in very 
different ways following a patient's admission. Information relating to previous admissions to hospital was usually not available to staff during the early stages of assessment and admission.

Our observations indicated that results and reports from clinical investigations and tests were highly structured and easily retrieved electronically when required. These patient data were also highly valued and frequently discussed at MDT meetings. In contrast, the documentation and retrieval of assessments by nurses and therapy staff, for example, posed several challenges. Their assessment practices and methods differed, and the narratives they generated were guided by professional regulation, accountability and legal requirements. The need for information to be framed in particular ways led to similar information having to be sought repeatedly from patients or relatives:

We're all looking for information about different things in a way - nurses, therapists and social workers. We all like the information to be got from us in a way that's fresh. So, we [nurses] might read what somebody else has written but we still like to be 'I've spoken to that family member and got that information'. But the therapists, when they're talking to family members, might have a different agenda for getting the information than we have. (Nurse manager, Site B)

The professional assessments also had varied currency across other professional groups because the narratives were long and framed in particular ways that others sometimes found irritating or obfuscating. There also appeared to be a lack of trust in the assessment of others' professional judgement:

Ward staff and social workers do not know each other very well and therefore might be less willing to trust each other's decisions. (Fieldnotes, Site A)

You've got to be able trust that your colleagues know what we are doing ... and at the moment I think there isn't that trust ... because we don't feel that people actually know what our aim is here. (Senior occupational therapist, Site B)

Patients' personal histories, or 'collateral' as it was often referred to by hospital staff, was a heterogenous collection of information about an individual patient's life that could provide the context for clinical information. Yet the importance of accurate information about cognitive function and home circumstances was often overlooked even when it could be crucial for differentiating between acute and chronic cognitive impairment, a vital difference affecting clinical decision-making. 'Getting the story right' was crucial but not recognised by many working in non-geriatric settings where many OPLWF were accommodated. The comment 'patient is more confused than usual', frequently found in notes and handovers during this study, did not help identify if the confusion was an acute and fluctuating disturbance in cognition resulting from the current medical crisis or if the patient had preexisting cognitive difficulties. This is illustrated in the excerpts below:

Ethel has fallen over. Yes, she's a bit confused, let's just say it's a UTI [urinary tract infection] and admit her under the medics. The time that that takes the ED 
[Emergency Department] doctor to do, 30 minutes. Whereas actually Ethel isn't confused, she has a diagnosis of dementia, she's no worse. Yes, she has fallen over, but that's because she tripped over the cat again. (Senior geriatrician, Site B)

Patients are readmitted unnecessarily and again, the process of assessing them starts because any confusion, you don't know how long it's been there, so you treat as a delirium. So all the assessing process starts, getting investigations, getting a CT brain and then we put them in hospital. (Consultant physician, Site B)

This 'collateral' information about patients and their stories was mostly unstructured and likely to not be recorded at all, lost or not accessed even if it was available, as indicated in the excerpt below, pointing to how little this information was valued:

That's usually the stuff that we miss out. We remember to hand over medical stuff, the really high priority stuff, but in terms of conversations that we've had with family in terms of the qualitative stuff, we sometimes forget to document the details or to have a discussion about the details. (Ward sister 2, Site B)

Even when Comprehensive Geriatric Assessments (CGA $\left.{ }^{3}\right)($ Parker et al., 2017) were carried out by specialist teams prior to a patient's admission, this information was vulnerable to loss:

The [discharge role] told me about the CGA, a thorough assessment of the patient including collateral information which is key information to help patient discharges that the team complete when they first review the patient. If the patient then is admitted to [another] ward, this information is at risk of being lost ... She felt that this information is lost/overlooked or inaccessible and that the staff do not recognise its value. (Fieldnotes, Site A)

While this information about patients and their stories appeared not to have been given high priority, some participants, especially those working in specialisms related to the care of OPLWF, clearly described its importance and role in facilitating diagnosis, treatment decisions and discharge planning:

If we just deal with the acute problem, you tend to miss the bigger picture, so that's why we gather all that information and then make a plan which involves early discussions with the relatives ... so pulling all of that together and moving forward. It takes an element of assimilation and planning and helping. (Consultant geriatrician, Site A)

I used to find it frustrating that I'm not allowed to spend half an hour talking to someone but I am allowed to charge the hospital for an X-ray, blood tests and blah, blah, so you do that instead of talking to the person. But then as you develop as a doctor, you realise that actually that doesn't give you as much information as spending half an hour talking to them. So now I spend half an hour talking to them and I order less tests. (Junior doctor, Site B) 
General practitioners (GPs) taking part in this study also described the importance and function of this information for planning and co-ordinating, as illustrated below:

Gathering of information very early in the hospital's journey is absolutely critical to good discharge planning and checking that the structures that were working before the acute illness were working, is key really to anticipating discharge planning and the board round is key to that, board round and huddles are key to gathering that information and junior doctors and nursing staff and the discharge co-ordinators will try and gather as much as possible so we know where we are going with the patient. (GP, Site A)

[Social workers] go like if somebody is 85 years old so what job did she used to do and how many kids she has got and so on, but in a concise manner where it makes you a picture of that person and what's her mobility like and what does she like to be called and etc., that's still better. Social workers probably have a couple of hours and the junior doctor may have just ten minutes to summarise everything. (GP, Site B)

These accounts suggest that this information was recognised by some participants as playing an important role from the time of presentation in the Emergency Department, to admission to discharge, and that it had clinical and diagnostic relevance, and was required for safe care co-ordination. Yet it was usually incomplete or missing. Our observations provided evidence about the reasons for this. These were threefold: first, this information was often not collected because of the pressures in an acute care environment made it difficult for staff to take the time to speak to patients and family members; second, even if hospital staff had these important conversations, they were often not documented because again it was perceived to be time-consuming; and third, even if this information was documented in some way, it often could not be accessed easily by other staff and therefore failed to be integrated into decision-making. For example, we observed some staff making notes on paper printouts of handover sheets which may have been passed on verbally but not entered into any formal channels of communication. Some information gathered from conversations with family members was also documented as part of a structured clinical examination but tended to reduce patients to narrative 'factoids' (Greenhalgh et al., 2014) such as 'more confused than usual'.

Hospital admission resulted in the collection of information by different professionals in a mixed economy of information storage, both paper and electronically on a variety of different systems. These systems were not universally accessible either across the hospital or with community care providers which led to fragmentation and militated against a holistic understanding of the patient who became 'de-constructed'. Our observations also provided evidence that patients' de-construction was exacerbated by other factors including a lack of continuity of care and communication. This was the result of low staffing levels; 12-hour shift patterns for nurses who worked more hours on fewer days of the week; patients being moved to other wards to improve the hospital bed capacity; as well as factual inaccuracies and distortions during handover meetings. This 
de-construction had consequences for patients' outcomes and was implicated in delays in discharges or care transitions as we describe in the following section. However, it also left family members and carers frustrated and alienated, as the following interview extracts illustrate:

The worst part is their systems just appear to be broken ... You would never see the same doctor twice; you rarely see the same nurse twice. Doctors were coming in and saying, 'I am new to your case' and they were turning to me and saying 'what's wrong with your wife'. I would think 'well aren't you supposed to be telling me that'? She had never had a proper diagnosis ... She kept getting moved between one ward and another as well, there was no continuity so we saw this series of doctors, all of which had their own theories and she came home with some medication, no particular discharge plan and then she was just left to cope. (Husband/ carer, Site A)

Quite often you are asked for a history ... it's distressing enough as it is ... It felt like each time I went to visit Mum over the next week, I met a different nurse who wrote things down on a piece of paper in Mum's file and that I assumed was the continuity, but each time I felt like I was explaining the same thing. It was like Groundhog Day. (Daughter/carer, Site A)

\section{Re-construction}

The information fragments described above had to be re-integrated to make sense of what was needed to discharge a patient from acute hospital care and match it against patients' capabilities and family, community and social care resources. This post-discharge landscape of health and social care resources at both study sites was complex and fluctuating, and hospital staff were often unaware of changes in provision and availability. We observed a wide range of processes at both study sites - long-established and newly implemented - to bring together the information fragments that had been collected over the course of a patient's admission, and match them with available community resources. We refer to these activities as 're-constructing the patient'. This process involved (a) attempts to assemble a complete picture of the older person living with frailty to enable discharge and (b) identifying rehabilitation, care and support needs, and how they could be met at the patient's usual place of residence or onward care.

Both study sites had recognised the importance of and had set up structures and processes to enable communication and care co-ordination. These could be said to be aimed at patient re-construction. They included MDT meetings which usually happened once or twice a week, and the more recently established 'board rounds' (NHS Improvement, 2017) and 'huddles' (NHS Improvement, 2019) which happened at least daily. Another re-construction tool was the discharge summary, usually written by junior hospital doctors. Its purpose was to communicate relevant and accurate information to enable the safe transition of care from hospital to community setting. This was in a highly structured electronic form and took at least 30 minutes to complete. Summaries rarely contained social information. This could have been due to the design of the form, but also the multiplicity and volume of 
information pieces collected during an admission. This was likely to lead to information overload with salient patient information being obscured by less relevant or repetitive clinical data.

Both study sites had specialist multi-professional teams supporting the assessment and care of OPLWF. They had also introduced specialised integrated, multidisciplinary discharge services for patients with complex needs, with a range of co-ordinating roles such as discharge nurses, case managers and discharge trackers. Specific processes differed but were aligned in their purpose to bring together information collected about individual patients at the point at which they were assessed to no longer need acute hospital care, or 'medically fit for discharge'. Daily review meetings by senior staff from health and care organisations in the local system and hospital discharge co-ordinators took place to assess patients' ongoing needs. This was done based on online forms completed by ward staff. While the aim of these reviews was to be comprehensive, our observations yielded little evidence of the active involvement of patients or family members in the re-constructing process:

[Hospital stay] is still a very passive 'You're not very well, we're going to do lots of investigations, we're going to find out everything that's wrong with you, we're going to treat everything', and the patients are very passive recipients of this. They're passengers in this process. (Senior community health-care provider, Site A)

Re-construction was difficult and time-consuming, and often left to junior members of the medical team who were responsible for generating discharge summaries to onward care providers and GPs. Social workers also played a crucial role in integrating existing data they may have held about patients with the information fragments generated by patients' hospital admissions:

I also use a [specific IT system] update system. Couple of problems with that is we have realised that wards can delete what you have said so that can lead to a whole world of problems there. (Social worker, Site A)

We would get the patient's point of view on what they want, and you have to assess their capacity as well. We look at the person as a whole. You know, get a bit of background information ... We have background history, and we have to put past medical history within that as well to find out how they communicate, if they need an interpreter. Then going through all the individual things like personal care and nutrition which is all the outcomes really. (Social worker, Site B)

The fieldnotes below are illustrative of the challenges involved in finding information, requiring time and 'detective work' because it was held in different locations:

They were looking in his notes, they were looking on [IT system] for a list of investigations and results and were looking on [IT system] for notes about previous admissions and treatments. This must have taken between five and ten minutes and they were still left with a lot of uncertainty about what had happened to him both recently and in the past. The junior doctor joked that it was like being a detective trying to find and then piece together all the information. (Fieldnotes, Site A) 
These accounts suggest that even for basic clinical information retrieval, staff encountered obstacles. Assembling these data to produce a holistic picture of a patient's clinical condition, socio-economic context, care and support networks, as well as their and their family's wishes, was often hampered by a lack of information. Our observations indicated that this uncertainty led to an avoidance of making decisions because of the risks associated with OPLWF. Instead, participants talked about 'passing the risk on' by referrals to specialist hospital teams such as those for psychiatric conditions, diabetes or other chronic conditions. Waiting for these assessments to be completed, reported and reviewed often added several days to a patient's hospital stay.

Risk perceptions and the willingness to make decisions were based on the quality of the re-construction process. The presence of clear information about patients' social circumstances and support networks enabled professionals to make decisions that in some cases avoided patients losing their independence and the escalation of care needs. The following account describes how through dialogue and problem-solving, a way to enable a patient to remain in her own home was found and a move to residential care was averted, at least for a time. While this solution would apply to only a few cases, this account illustrates how a holistic understanding of OPLWF is more likely to lead to creative approaches to managing risk than the information pieces generated in the de-construction process which reduce patients to narrative 'factoids':

She had been living at home on her own. She'd got a friend who used to come every day from lunchtime till about 11 o'clock at night and then he'd go home. She had family who were supportive but lived overseas so they couldn't support ... She really wanted to go home. She had fallen previously so was supposed to sleep downstairs but every now and again she'd go upstairs because she wanted to get something out of the bedroom. The therapists really did not want her to go home because their view was that she was at risk of falling and if she went upstairs, she was at risk of seriously injuring herself ... So I had several calls with her grandson who was abroad. Then we had a case conference with him included via telephone and she understood the risks. They put a small gate on the bottom of the stairs so she knew that she wasn't supposed to go up and if she needed anything, maybe to go up when her friend visited. Her friend was going to stay for the first couple of nights overnight. She went home and she stayed at home. (Senior nurse manager, Site B)

Apart from the knowledge of the patient's social context, the way hospital staff communicated with their colleagues in community-based services also shaped the re-construction process. Direct communication with a GP described in the account below was more likely to lead to a better experience for the patient and family, and demonstrates how hospital readmission could be avoided:

What made [the discharge] good was that somebody communicated directly with me, and so I knew what the problem was. So, this was unexpected - they'd bothered to tell me, because they could have put nothing and - but the fact they'd thought, okay, this patient is going to die in the next few weeks, what would 
need to be in place to not get them back into hospital? Actually - and they had talked to the relatives. So the relatives already knew and I wasn't running round trying to find the relatives in the middle of evening surgery to go, 'Are you aware of this? And by the way...' (GP, Site A)

These examples of 'successful' patient re-construction share two essential components: good multi-professional communication and co-ordination, rather than a focus on specialist assessments, and the involvement of patients and family members in decision-making. These are encapsulated in the following interview excerpt:

So rather than having that sort of 'we're waiting for the OT [occupational therapist] to come and assess' and 'we're waiting for the social worker', [instead] how do you build up and have that shared inter-disciplinary discussion, that sort of broader discussion around actually what's happening with the person, what do they want, what's their wishes? So where are we trying to get to ... and what are the steps to make that happen? Rather than looking at it through an assessment lens. (Senior health system lead, Site B)

\section{Discussion}

The study aim was to understand why delays occur in the discharge of OPLWF and identify obstacles that may be amenable to local solutions with potentially wider application across other health and care systems. Our findings indicate that working practices in the study hospitals may have inadvertently contributed to delays because many pieces of information about a patient were collected, recorded and accessed in different ways by different professionals. In order to facilitate a discharge, these pieces needed to be re-found, integrated and re-constructed. A key component of this integration and re-construction process was information related to patients' social, family and functional background - their human story. However, we observed that this was often missing, or even if it was collected and stored, it was not necessarily accessed and was vulnerable to loss, especially if patients were moved to different wards. It was also perceived to be of low value in relation to other more readily available information such as results from clinical investigations and assessments. Patients' re-constructions were thus often incomplete, or insufficient to reduce the clinical and prognostic uncertainty associated with frailty and manage risks inherent in OPLWF's discharge. On the other hand, where this key component was present and integrated into decision-making processes in MDT working, uncertainty and risk were managed more constructively than when it was absent, and this sometimes avoided an escalation of care needs. Knowing about the life and circumstances of the older person living with frailty was not just about humanising their care, it was central to safe care and the appropriate use of resources.

The lack or loss of vital patient information has previously been linked to poor inter-organisational care co-ordination and continuity of care (The Health Foundation, 2013; Fillingham et al., 2016; Sheaff et al., 2017; Crisp et al., 2020). It was also was connected to patients' involvement in decision-making and that of their family members or carers. Findings from this study and previous research 
(Huby et al., 2004, 2007; Efraimsson et al., 2006) indicate that highly structured communication practices in health-care settings often exclude older patients and limit their participation in decision-making because professional concerns about removing uncertainties and minimising risk tend to dominate. Furthermore, tacit assumptions by staff that self-determination may be less important with increasing age lead to safety being prioritised over the rights and values of older patients in decisions likely to affect profoundly the quality of their lives (Durocher et al., 2017). Our observations showed how professional lenses or 'gazes' (Foucault, 1975) view the patient from many different angles according to their disciplinary or professional criteria, segmenting the patient and redefining their needs (Mol, 2003). As Waring and Bishop (2020) suggest, these different perspectives struggle and compete with each other at the point of discharge, often failing to bring them together to form a holistic understanding of patient situation and develop patient-centred, co-ordinated discharge plans (Waring and Bishop, 2020). They argue that bureaucratic practices - such as we observed in this study - serve to compound this problem of segmentation by transforming complex patient needs into ticks on checklists or descriptors on drop-down menus, with algorithms determining whether or not patients are eligible for particular services and allocating responsibilities to specific staff or organisations. We found that this led to significant 'blind spots' and gaps in knowledge because relevant information about the formal and informal care providers involved in patients' care was not available. We suggest, based on our findings, that these latent patterns of routine working lead to failures in patient re-construction that in turn result in delays in older patients being discharged. The consequences include risks of patients' functional decline and loss of independence, patients and families being left feeling their needs have not been met adequately, and scarce health-care resources being used inefficiently.

Our study was limited by the number of hospital sites and the total number of patient journeys we could follow. However, the immersive data collection methods enabled us to generate in-depth data and develop insights from the perspectives of multiple stakeholders. This led us to a novel conceptualisation of what happens to OPLWF when they are admitted to hospital as an emergency (de-construction) and to identify reasons for delays in their discharge beyond the well-known obstacles (failures in re-construction).

In collaboration with our research partners, including public contributors, we have identified three principles based on our findings that could underpin the development of interventions to mitigate the problem of delayed discharges for OPLWF. First, we suggest mobilising the metaphor of patient de-construction and re-construction to raise awareness among the teams responsible for discharge planning and care co-ordination of the key role of patients' social, family and functional background information. Achieving a hospital discharge is a highly complex task and requires complex patterns of care organisation by many professionals. As such, it is a 'problem of many hands', described by Dixon-Woods and Pronovost (2016) as a challenge arising where numerous individuals and organisations contribute to an outcome, but no single actor has overall responsibility for it (Dixon-Woods and Pronovost, 2016). While structural barriers to timely discharges for OPLWF such as insufficient capacity in the social care sector have to be addressed at the national and system level, the problem of many hands in the 
de- and re-construction processes of OPLWF could be supported by the focused collection, central storage and ready retrieval of patient information. A recognition of its value beyond a single professional assessment may contribute to a more holistic understanding of OPLWF in the context of their lives and facilitate personcentred decision-making around discharge planning and care co-ordination.

Second, we propose that the introduction of new electronic forms avoids standardisation and bureaucratisation. These carry with them the risk of further patient segmentation and the reduction of patients to units of need, required to conform with a range of criteria such as the eligibility to services (Waring and Bishop, 2020). Where possible, communication systems should allow for personal communication between professionals and the exchange of narrative information rather than of 'factoids' or lists of tick boxes in standardised forms.

Third, we are working with patient and carer organisations to highlight to them the key role of patients' social, family and functional background information, or 'information about me' as we have called it in a public-facing short animation (https://www.youtube.com/watch?v=nhOFWX5sQP0). The aim is to encourage a dialogue between patients, their family members or carers, and health and care professionals about this information that is recognised by all parties as being important in facilitating a successful discharge, in other words where risks are managed holistically and the arrangements made as a result are lasting and sustainable. This will require professionals requesting the information from patients and documenting it in a consistent manner, appropriate not only for their own assessment, but also meeting the needs of other professionals, thus avoiding repeated requests for the same or similar information from patients or family members. Patients and carers will also be encouraged to provide this information, preferably already captured in a text or electronic format that can be shared with and accessed by health and care staff. This bi-directional information exchange is important to avoid the onus of 'knowledge brokering' being placed solely on patients and carers, who might be expected to fill gaps in information and mediate between different professionals (Bishop and Waring, 2017). Our findings demonstrate that carers were left feeling distressed and alienated if they were placed into such a situation. Instead, we suggest that the role of patients and family members or carers in the de- and re-construction processes is recognised and encouraged, given that they are often the only source of continuity across a multi-professional/organisational pathway of care (O'Hara et al., 2019). We suggest that such a partnership approach values information about the lives of OPWLF as an essential component of discharge planning and care co-ordination, and may mitigate some of the alienating effects of the bureaucratic practices introduced to manage the organisational complexities of realising timely hospital discharges.

Supplementary material. The supplementary material for this article can be found at https://doi.org/10. 1017/S0144686X21000805

Acknowledgements. We would like to thank the staff at both hospitals who assisted in the identification and recruitment of patients, and the patients and families, and the health and social care staff who participated.We would also like to thank our public contributors and the project steering group for their thoughtful advice and guidance. 
Author contributions. SR: conceptualisation (equal); methodology (equal); writing - original draft (lead); formal analysis (equal); writing - review and editing (equal). HB: investigation (equal); formal analysis (equal); project administration (equal); writing - review and editing (equal). AM: investigation (equal); formal analysis (supporting); writing - review and editing (supporting). GC: methodology (equal); formal analysis (supporting); writing - review and editing (supporting). KN: conceptualisation (equal); methodology (equal); formal analysis (supporting); writing - review and editing (supporting). CT: investigation (supporting); formal analysis (equal); writing - review and editing (equal). SD: formal analysis (equal); writing review and editing (supporting). NM: investigation (equal); formal analysis (equal); writing - review and editing (supporting). EH: project administration (equal); writing - review and editing (supporting). SG: methodology (equal); formal analysis (supporting); writing - review and editing (equal). JLD: conceptualisation (equal); methodology (equal); writing - review and editing (equal).

Financial support. This research was supported by the National Institute for Health Research Applied Research Collaboration (NIHR ARC) West and NIHR ARC West Midlands. The views expressed in this article are those of the authors and not necessarily those of the NIHR or the Department of Health and Social Care.

Ethical standards. The study was approved by the West Midlands - Coventry \& Warwickshire Research Ethics Committee (reference 18/WM/0164).

\section{Notes}

1 This is the term preferred by public contributors to this study.

2 FRAILsafe was developed by the British Geriatrics Society as clinical criteria to identify accurately patients at risk of frailty-associated harm on admission to hospital.

3 The CGA is a multi-disciplinary process and management of assessed need which is now the accepted gold standard for caring for OPLWF in hospital.

\section{References}

Alvesson M and Sköldberg K (2018) Reflexive Methodology: New Vistas for Qualitative Research. London: Sage.

Bate A (2017) Delayed Transfers of Care in the NHS (House of Commons Briefing Paper No. 7415). Available at https://commonslibrary.parliament.uk/research-briefings/cbp-7415/.

Bauer M, Fitzgerald L, Haesler E and Manfrin M (2009) Hospital discharge planning for frail older people and their family. Are we delivering best practice? A review of the evidence. Journal of Clinical Nursing 18, 2539-2546.

Bishop S and Waring J (2017) The knowledge brokering situations of care transitions. In Aase K, Waring J and Schibevaag L (eds), Researching Quality in Care Transitions: International Perspectives. Cham, Switzerland: Springer International Publishing, pp. 159-178.

Braun V and Clarke V (2006) Using thematic analysis in psychology. Qualitative Research in Psychology 3, 77-101.

Braun V and Clarke V (2019) Reflecting on reflexive thematic analysis. Qualitative Research in Sport, Exercise and Health 11, 589-597.

Charmaz K (2006) Constructing Grounded Theory: A Practical Guide Through Qualitative Analysis. London: Sage.

Corrigan O, Georgiadis A, Davies A, Pauline L, Milne E, Speed E and Wood D (2016) Insights into Hospital Discharge: A Study of Patient, Carer and Staff Experience in Essex. Feering, UK: Healthwatch Essex. Available at https://www.healthwatch.co.uk/sites/healthwatch.co.uk/files/reportslibrary/20160604_ Essex_Insights\%20into\%20hospital\%20discharge.pdf.

Crisp H, Watt A, Jones B, Amevenu D and Warburton W (2020) Improving Flow Along Care Pathways. London: The Health Foundation.

Department of Health (2007) Guidance on Nominating a Consultee for Research Involving Adults Who Lack Capacity to Consent. London: Department of Health. 
Dixon-Woods M and Pronovost PJ (2016) Patient safety and the problem of many hands. British Medical Journal, Quality \& Safety 25, 485-488.

Durocher E, Gibson BE and Rappolt S (2017) Mediators of marginalisation in discharge planning with older adults. Ageing \& Society 37, 1747-1769.

Efraimsson E, Sandman P-O and Rasmussen BH (2006) 'They were talking about me' - elderly women's experiences of taking part in a discharge planning conference. Scandinavian Journal of Caring Sciences 20, 68-78.

Fillingham D, Jones B and Pereira P (2016) The Challenge and Potential of Whole System Flow. London: The Health Foundation.

Foucault M (1975) The Birth of the Clinic: An Archaeology of Medical Perception. New York, NY: Vintage Books.

Greenhalgh T, Howick J and Maskrey N (2014) Evidence based medicine: a movement in crisis? British Medical Journal 348, Article No. g3725.

Hoogendijk EO, Afilalo J, Ensrud KE, Kowal P, Onder G and Fried LP (2019) Frailty: implications for clinical practice and public health. The Lancet 394, 1365-1375.

Huby G, Stewart J, Tierney A and Rogers W (2004) Planning older people's discharge from acute hospital care: linking risk management and patient participation in decision-making. Health, Risk \& Society 6, $115-132$.

Huby G, Brook JH, Thompson A and Tierney A (2007) Capturing the concealed: interprofessional practice and older patients' participation in decision-making about discharge after acute hospitalization. Journal of Interprofessional Care 21, 55-67.

Jasinarachchi KH, Ibrahim IR, Keegan BC, Mathialagan R, McGourty JC, Phillips JRN and Myint PK (2009) Delayed transfer of care from NHS secondary care to primary care in England: its determinants, effect on hospital bed days, prevalence of acute medical conditions and deaths during delay, in older adults aged 65 years and over. BMC Geriatrics $9,4$.

King's Fund (2018) Delayed Transfers of Care: A Quick Guide. London: King's Fund. Available at https:// www.kingsfund.org.uk/publications/delayed-transfers-care-quick-guide\#why-are-they-important.

Kortebein P (2009) Rehabilitation for hospital-associated deconditioning. American Journal of Physical Medicine \& Rehabilitation 88, 66-77.

Lafont C, Gérard S, Voisin T, Pahor M, Vellas B and the Members of IAGG/AMPA Task Force (2011) Reducing 'iatrogenic disability' in the hospitalized frail elderly. Journal of Nutrition, Health \& Aging 15, 645-660.

Mol A (2003) The Body Multiple: Ontology in Medical Practice. London: Duke University Press.

National Audit Office (2016) Discharging Older Patients from Hospital. London: National Audit Office. Available at www.nao.org.uk/report/discharging-older-patients-from-hospital.

NHS England (2017a) Better Care Fund. London: NHS England. Available at https://www.england.nhs.uk/ ourwork/partrel/transformation-fund/bcf-plan/.

NHS England (2017b) Delayed Transfers of Care. London: NHS England. Available at https://www.england. nhs.uk/statistics/statistical-work-areas/delayed-transfers-of-care/.

NHS Improvement (2017) SAFER Patient Flow Bundle: Board Rounds. London: NHS Improvement. Available at https://improvement.nhs.uk/resources/safer-patient-flow-bundle-board-rounds/.

NHS Improvement (2019) Safety Huddles. London: NHS Improvement. Available at https://improvement. nhs.uk/resources/safety-huddles/.

O'Hara JK, Aase K and Waring J (2019) Scaffolding our systems? Patients and families 'reaching in' as a source of healthcare resilience. British Medical Journal, Quality \& Safety 28, 3-6.

Oliver D, Foot C and Humphries R (2014) Making Our Health and Care Systems Fit for an Ageing Population. London: King's Fund. Available at https://www.kingsfund.org.uk/sites/default/files/field/ field_publication_file/making-health-care-systems-fit-ageing-population-oliver-foot-humphries-mar14.pdf.

Papoutsi C, Poots A, Clements J, Wyrko Z, Offord N and Reed JE (2018) Improving patient safety for older people in acute admissions: implementation of the Frailsafe checklist in 12 hospitals across the UK. Age and Ageing 47, 311-317.

Parker SG, McCue P, Phelps K, McCleod A, Arora S, Nockels K, Kennedy S, Roberts H and Conroy S (2017) What is Comprehensive Geriatric Assessment (CGA)? An umbrella review. Age and Ageing 47, 149-155. 
Royal College of General Practitioners and British Geriatric Society (2016) Integrated Care for Older People Living with Frailty. London: British Geriatric Society.

Schoepfle GM and Werner O (1999) Ethnographic debriefing. Field Methods 11, 158-165.

Sheaff R, Halliday J, Byng R, Øvretveit J, Exworthy M, Peckham S and Asthana S (2017) Bridging the discursive gap between lay and medical discourse in care coordination. Sociology of Health \& Illness 39, 1019-1034.

The Health Foundation (2013) Improving Patient Flow. London: The Health Foundation.

Waring J and Bishop S (2020) Health states of exception: unsafe non-care and the (inadvertent) production of 'bare life' in complex care transitions. Sociology of Health \& Illness 42, 171-190.

Waring J, Marshall F, Bishop S, Sahota O, Walker M, Currie G, Fisher R and Avery T (2014) An Ethnographic Study of Knowledge Sharing Across the Boundaries Between Care Processes, Services and Organisations: The Contributions to 'Safe' Hospital Discharge. Southampton, UK: NIHR Journals Library.

Waring J, Marshall F and Bishop S (2015) Understanding the occupational and organizational boundaries to safe hospital discharge. Journal of Health Services Research \& Policy 20, 35-44.

Wilson A, Baker R, Bankart J, Banerjee J, Bhamra R, Conroy S, Kurtev S, Phelps K, Regen E, Rogers S and Waring J (2015) Establishing and Implementing Best Practice to Reduce Unplanned Admissions in Those Aged 85 Years and Over Through System Change [Establishing System Change for Admissions of People 85+ (ESCAPE 85+)]: A Mixed-methods Case Study Approach. Southampton, UK: NIHR Journals Library.

Cite this article: Redwood S et al (2023). How latent patterns of interprofessional working may lead to delays in discharge from hospital of older people living with frailty - 'Patient more confused than usual?'. Ageing \& Society 43, 576-597. https://doi.org/10.1017/S0144686X21000805 